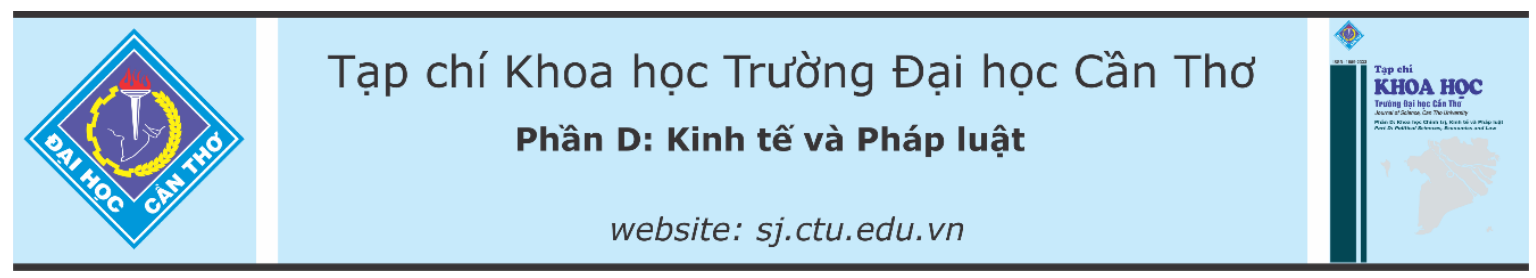

DOI:10.22144/ctu.jvn.2021.135

\title{
CÁC YẾU TỐ TÁC ĐỘNG TỚI BIỆN PHÁP PHÒNG DỊCH TẢ HEO CHÂU PHI CỦA NÔNG HỘ TẠI TỈNH ĐỒNG NAI
}

\author{
Hoàng Hà $\mathrm{Anh}^{*}$ và Lê $\mathrm{Na}$ \\ Khoa Kinh tế, Trường Đại học Nông Lâm Thành phố Hồ Chi Minh \\ *Nguời chịu trách nhiệm về bài viết: Hoàng Hà Anh (email: hoanghaanh@hcmuaf.edu.vn)
}

\section{Thông tin chung:}

Ngày nhận bài: 02/02/2021

Ngày nhận bài sủa: 06/06/2021

Ngày duyệt đăng: 20/08/2021

\section{Title:}

Factors influencing preventative measures against African swine fever of farming households in Dong Nai province

\section{Tù khóa:}

Dịch tả heo Châu Phi, hành động phòng dịch, người nuôi heo

\section{Keywords:}

African swine fever, pig raising farmers, preventative measures

\begin{abstract}
This study was conducted to analyze factors influencing the number of preventative measures against African swine fever that pig raising households in Dong Nai province had been implemented from collected data from 140 households using convenience sampling. The KAP framework (Knowledge-Attitude-Practice) and Poisson regression model were used. Research results showed that the number of households whose swines were infected accounted for $70 \%$ of the surveyed sample, and the scale of damage was mostly below 200 swines per household. Pig raising farmers can recognize several symptoms of the disease, but there remained some warning signs that were not compeletely noticed. Most of the households implemented 9 to 12 preventative measures at their farms, accounting for $65 \%$ of the sample. The regression results revealed that variables having statistically significant and positive correlation with the amount of implemented preventative measures were knowledge, the level of anxiety about risks of infection, and experience in dealing with previous diseases. Thus, if swine households have better knowledge of the disease, have more experience from dealing with previous infectious diseases, and worry about the infectious risks of their swines, they will be more active in implementing preventative measures.
\end{abstract}

\section{TÓM TẮT}

Nghiên cưu này được thục hiện nhằm phân tích các yếu tố ảnh hưởng tới số lương biện pháp phòng dịch tả heo Châu Phi các nông hộ đã áp dụng tại tỉnh Đồng Nai tù số liệu điều tra 140 hộ chăn nuôi heo bằng phuoong pháp chọn mẫu thuận tiện. Khung phân tích KAP (Knowledge-AttitudePractice) và mô hình hồi quy Poisson được sử dụng. Kết quả cho thấy tỷ lệ hộ có đàn heo bị nhiếm bệnh lên tới $70 \%$ trong mẫu khảo sát. Người nuôi heo có kiến thức căn bản để nhận biết bệnh dịch nhung vẫn có một số dấu hiệu của bệnh chưa được nắm rõ. Đa phần các hộ chăn nuôi đều áp dụng tù 9 đến 12 biện pháp an toàn sinh học phòng dịch bệnh cho trang trại heo, chiếm tỷ lẹ 65,0\%. Kết quả uớc luợng của mô hình cho thấy các biến có ý nghĩa thống kê và tác động tích cực lên số lượng biện pháp phòng dịch của nông hộ là kiến thức, mức độ lo lắng lây nhiếm, khoảng cách và kinh nghiệm phòng dịch. 


\section{GIỚI THIỆ}

Chăn nuôi heo là ngành kinh tế nông nghiệp truyền thống, quan trọng, đóng góp lớn vào phát triển kinh tế xã hội cho tỉnh Đồng Nai, là nguồn cung cấp thực phẩm, tạo công ăn việc làm và thu nhập cho người dân. Từ năm 2000 , ngành chăn nuôi heo tỉnh Đồng Nai phát triển mạnh từ mô hình chăn nuôi hộ gia đình sang chăn nuôi trang trại (Lê Thị Mai Hương, 2017). Đồng Nai là địa phương phát triển ngành nuôi heo mạnh nhất cả nước, tổng đàn năm 2017 là 1.698,1 nghìn con, thống kê sơ bộ năm 2018 là 1.773,6 nghìn con (Tổng cục thống kê, 2020). Tuy nhiên, trong quá trình chăn nuôi, các dịch bệnh truyền nhiễm đã gây tác động lớn đến người nuôi heo cả về kinh tế lẫn quy mô đàn.

Bệnh dịch tả heo Châu Phi (DTHCP) (African swine fever - ASF) ảnh hưởng đến tất cả các giống heo và các độ tuổi. Đây là bệnh gây ra bởi loài virus có AND phức hợp của dòng họ Arviridae (BeltranAlcrudo et al., 2017). Loài virus có sức đề kháng đặc biệt với môi trường, hiện nay chưa có thuốc đặc trị và chưa có vaccine phòng ngừa, nên tỷ lệ heo mắc bệnh rồi chết lên đến $100 \%$ (FAO, 2019). Khi bệnh DTHCP xuất hiện dẫn đến những vấn đề nghiêm trọng đối với giới chức thú y nói riêng và ngành công nghiệp chăn nuôi heo nói chung.

Tại Việt Nam, ngày 19/02/2019, Chi cục Thú y (Bộ Nông nghiệp và Phát triển Nông thôn) thông báo phát hiện ổ bệnh DTHCP đầu tiên tại tỉnh Hưng Yên và Thái Bình. Ngày 17/04/2019, tỉnh Đồng Nai phát hiện ổ bệnh DTHCP đầu tiên tại huyện Trảng Bom, đến 31/12/2019 bệnh DTHCP đã xảy ra tại 5.371 cơ sở chăn nuôi heo của 137 xã, phường, thị trấn. Tỉnh đã tiêu hủy khoảng 450.000 con heo với tổng trọng lượng 23.930 tấn, làm đàn heo trên địa bàn giảm $19,41 \%$ so với thời điểm trước dịch (Nguyễn Trí, 2020).

Đối với bệnh DTHCP và sự bùng phát của dịch bệnh này, đa phần các nghiên cứu đã thực hiện thuộc về lĩnh vực sinh học, thú $\mathrm{y}$, hay dịch tễ học nhằm tìm hiểu về loại virus gây ra dịch bệnh, cơ chế phát triển của virus, triệu chứng y học (Penrith, 2009; Vinuela, 1985), hay phương pháp chữa trị (Costard et al., 2013). Trong khi đó, các đề tài dưới góc độ kinh tế xã hội về bệnh DTHCP thường hướng về phân tích tác động lên nền nông nghiệp, các con đường lây nhiễm và xác suất lây nhiễm, đánh giá rủi ro lây nhiễm và tình trạng bùng phát của dịch bệnh này.

Swai and Lyimo (2014) đã đánh giá tác động của bệnh DTHCP lên kinh tế của các hộ nuôi heo nhỏ lẻ ở huyện Rombo, Tanzania. Kết quả cho thấy tỷ lệ heo chết khi mắc bệnh là $84 \%$, trung bình mỗi hộ mất từ $1-50$ con heo, nền kinh tế địa phương năm 2013 chịu tổn thất khoảng 70.000 USD. Tại Nga, Vergne et al. (2017b) đã sử dụng hàm space-time $\mathrm{K}$ để phân tích mô hình phân bố không gian-thời gian của các ổ dịch và các con đường lây nhiễm tại 2 vùng bị ảnh hưởng nhiều nhất của Nga là Krasnodar và Tver. Tiếp nối nghiên cứu này, Vergne et al. (2017a) phân tích rủi ro lây lan bệnh DTHCP vào Trung Quốc. Theo các tác giả, với nền kinh tế đang phát triển nhanh và phức tạp tại Trung Quốc thì việc kiểm soát bệnh DTHCP là vô cùng phức tạp và đòi hỏi một cách tiếp cận tổng hợp từ cả khoa học lẫn chính trị. Ngoài ra, sự hợp tác với các quốc gia láng giềng có chăn nuôi heo như Việt Nam, Thái Lan và Philippines là điều cần thiết.

Tại Việt Nam, hiện chưa có công trình khoa học nào được công bố liên quan tới bệnh DTHCP dưới góc độ kinh tế xã hội. Gần nhất vào năm 2019, Le et al. (2019) đã nghiên cứu về loại virus gây ra dịch tại Việt Nam năm 2019 và kết luận rằng nó trùng khớp với các virus phát hiện tại Trung Quốc năm 2018 và Georgia 2007.

Như vậy, có thể thấy rằng các nghiên cứu thuộc lĩnh vực kinh tế xã hội về bệnh DTHCP đa phần tập trung vào phân tích rủi ro và các con đường phát tán dịch, các đề tài này thường thực hiện ở cấp độ vĩ mô. Một điểm đáng chú ý là hẩu hết các nghiên cứu trước đều đề cập tới vai trò của hành vi con người hay cụ thể là của người nuôi heo trong việc phòng chống và thực hiện các biện pháp an toàn sinh học, nhưng chưa có nhiều nghiên cứu chi tiết về chủ đề này, đặc biệt là ở Việt Nam, nơi bệnh DTHCP đã bùng phát mạnh mẽ và gây thiệt hại lớn.

Trong quá trình phát triển của ngành chăn nuôi heo, chưa có loại bệnh truyền nhiễm nào khó kiểm soát và gây tổn thất lớn như bệnh DTHCP. Các biện pháp hiện tại để phòng chống lây nhiễm chủ yếu là áp dụng các biện pháp an toàn sinh học tại các cơ sở chăn nuôi. Theo ghi nhận của ngành thú $\mathrm{y}$, những trường hợp xảy ra bệnh $\mathrm{DTHCP}$ đa số là hộ chăn nuôi cá thề, chưa tiêm phòng đầy đủ các bệnh truyền nhiễm nguy hiểm, chưa áp dụng chăn nuôi an toàn sinh học, con giống được mua từ nhiều nguồn khác nhau. Vì vậy, hành vi của người nuôi heo là rất quan trọng để kiểm soát việc lây lan bệnh DTHCP. Các nghiên cứu trước đây cho thấy người chăn nuôi có thể có kiến thức và hiểu biết nhưng không có nghĩa là họ sẽ thực hiện các biện pháp phòng dịch (Chenais et al., 2017; Tiongco et al., 2012). Các cơ quan chính quyền đã đưa ra các biện pháp phòng tránh, xong 
dịch vẫn chưa có dấu hiện dừng lại và đang có nguy cơ tái nhiễm ở một số địa phương. Chính vì vậy một nghiên cứu dưới góc độ vi mô và tập trung vào người chăn nuôi heo là điều cần thiết để có thể hiểu được những nguyên nhân dẫn tới sự bùng phát nhanh chóng của dịch bệnh này tại các hộ chăn nuôi.

Trong bối cảnh đó, nghiên cứu này được thực hiện để phân tích các yếu tố ảnh hưởng tới hành động phòng bệnh DTHCP của các hộ nuôi heo tại tỉnh Đồng Nai. Qua kết quả này, đề tài tìm ra được các tác nhân thúc đẩy việc thực hiện các biện pháp phòng dịch, giúp cho các cơ quan phòng dịch đề xuất các giải pháp phòng dịch hiệu quả hơn.

\section{PHƯƠNG PHÁP NGHIÊN CÚU}

\subsection{Khung phân tích KAP}

Đối với chủ đề nghiên cứu là dịch bệnh trong chăn nuôi, đã có nhiều tác giả áp dụng khung phân tích KAP (knowledge, attitude, practice) để phân tích hành vi của con người. KAP là khung phân tích cho một tổng thể nghiên cứu để xác định về những gì được biết, tin tưởng, và được thực hiện liên quan đến một vấn đề cụ thể nào đó (WHO, 2008).

Fielding et al. (2005) điều tra 986 hộ gia đình tại Hong Kong bằng bảng câu hỏi được chia làm nhiều phần, kết hợp sử dụng thang đo Likert hoặc tính điểm cho câu trả lời. Di Giuseppe et al. (2008) cũng xây dựng bảng câu hỏi với cách tiếp cận tương tự và sử dụng thêm các hàm Logistic và hàm tuyến tính để đánh giá mức ảnh hưởng của các biến độc lập lên kiến thức và nhận thức của người chăn nuôi về bệnh dịch. Kết quả chỉ ra người chăn nuôi đã quen với loại bệnh dịch nhưng lại có hiểu biết hạn chế về các triệu chứng, đường lây truyền, và cách phòng dịch.
Tại Việt Nam, Pham-Duc et al. (2019) đã áp dụng KAP để phân tích hành vi sử dụng kháng sinh trong chăn nuôi gia súc, gia cầm và nuôi trồng thủy sản. Thông qua bộ số liệu từ 392 hộ chăn nuôi vừa và nhỏ, kết quả nghiên cứu cho thấy lý do chính để nông dân sử dụng kháng sinh là nhằm chữa nhiễm trùng $(69 \%)$. Những nông dân có kết quả về KAP tốt hơn thường là người bỏ ra nỗ lực để tìm kiếm thông tin về việc sử dụng kháng sinh. Tuy nhiên, có những trường hợp kiến thức cao và thái độ tốt lại không dẫn tới hành động tốt.

Trong nghiên cứu này, phương pháp tiếp cận của Huang (1993) và Jolly et al. (2009) được sử dụng để đề xuất khung phân tích. Các nghiên cứu này sử dụng mô hình để phân tích kinh tế và ra quyết định, trong đó bao gồm các yếu tố tâm lý, xã hội và cả phi kinh tế ảnh hưởng tới hành vi của người ra quyết định. Huang (1993) cho rằng nhận thức và thái độ của một cá nhân được tạo thành từ thông tin sẵn có, kiến thức, kinh nghiệm và cả những đặc điểm cá nhân, xã hội, văn hóa. Jolly et al. (2009) đã mở rộng phương pháp này và giả định rằng những kiến thức, nhận thức của một người cuối cùng sẽ phát triển thành thái độ nhằm thúc đẩy các hành động để tối thiểu hóa rủi ro. Trong đề tài này, dưới các giới hạn về nhân lực, thời hạn và kinh phí, đề tài chỉ tập trung vào phân tích thành phần "hành động thực tế" trong khung phân tích KAP để phòng dịch bệnh. Cụ thể, tác giả giả định rằng hành động thực hiện các biện pháp phòng bệnh DTHCP của nông hộ sẽ được quyết định thông qua kiến thức về dịch bệnh, thái độ đối với dịch bệnh, các đặc điểm của hoạt động chăn nuôi heo của hộ, và các biến nhân khẩu học và đặc điểm kinh tế xã hội (KTXH).

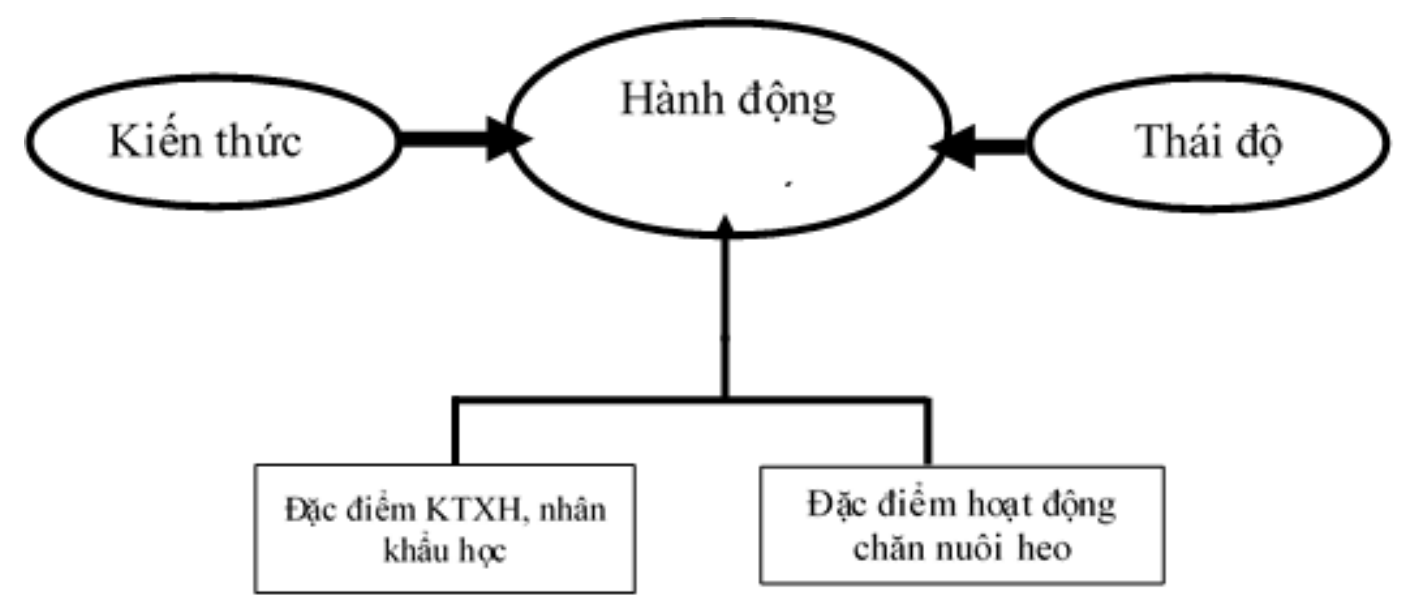

Hình 1. Khung phân tích đề xuất 


\subsection{Phương pháp phân tích}

\subsubsection{Uớc lương các yếu tố ảnh hưởng tới hành} động phòng dịch

Các yếu tố ảnh hưởng tới số lượng biện pháp phòng dịch bệnh mà hộ nuôi heo đã thực sự áp dụng đã được phân tích trong một số đề tài trước đây (Chenais et al., 2017; Tiongco et al., 2012). Tiongco et al. (2012) đã phát hiện rằng các hộ nghèo hơn có xu hướng thực hiện ít biện pháp an toàn sinh học hơn và từ đó đối mặt với rủi ro cao hơn về lây nhiễm dịch bệnh. Tương tự, Chenais et al. (2017) cũng đã kết luận rằng an toàn sinh học không đầy đủ là một trong những lý do dẫn tới bùng phát bệnh DTHCP tại Uganda. Trong mô hình này, số biện pháp phòng dịch là một hàm của kiến thức, thái độ và các biến đặc điểm khác của hộ nuôi heo. Để thực hiện phân tích này, hồi quy Poisson được sử dụng trong đó biến phụ thuộc chính là số đếm của số lượng biện pháp phòng bệnh DTHCP mà hộ nuôi heo đã thực hiện khi dịch xuất hiện năm 2019.

Mô hình Poisson là một ví dụ của mô hình tuyến tính tổng quát hóa (Generalized linear model GLM) (Gardner et al., 1995). Trong mô hình biến phụ thuộc $Y$ được giả định tuân theo phân phối Poisson (Tiongco et al., 2012), tức là $Y \sim \operatorname{Poisson}\left(\mu_{i}\right)$ với $\mathrm{i}=1, \ldots, \mathrm{N}$; giá trị kì vọng của $Y_{i}$ là $\mathrm{E}(\mathrm{Y})=\mu$. Gọi $X_{i}$ là các biến giải thích cho số lượng biện pháp mà hộ áp dụng. Mô hình hồi quy Poisson trong phân tích có dạng:

$$
g(\mu)=\beta_{0}+\sum_{k=1}^{K} \beta_{i} x_{i}+\varepsilon_{i}
$$

Các biến số trong mô hình được thể hiện trong Bảng 1.

Bảng 1. Các biến trong mô hình hồi quy

\begin{tabular}{|c|c|c|c|}
\hline $\begin{array}{l}\text { Tên } \\
\text { biến }\end{array}$ & Định nghĩa/Đo lường & $\begin{array}{c}\text { Kỳ } \\
\text { vọng } \\
\text { dấu }\end{array}$ & Nguồn tham khảo \\
\hline \multicolumn{4}{|c|}{ Biến phụ thuộc } \\
\hline$Y$ & $\begin{array}{l}\text { Số lượng biện pháp an toàn sinh học và phòng dịch đã áp } \\
\text { dụng }\end{array}$ & & $\begin{array}{l}\text { Chenais et al. (2017); } \\
\text { Fielding et al. (2005) }\end{array}$ \\
\hline \multicolumn{4}{|c|}{ Biến độc lập } \\
\hline$X_{1}$ & $\begin{array}{l}\text { Số điểm kiến thức về các triệu chứng lâm sàng của bệnh } \\
\text { DTHCP }(0-10 \text { điểm })\end{array}$ & + & $\begin{array}{l}\text { Leslie et al. (2008); } \\
\text { Suphunnakul and Maton } \\
\text { (2009) }\end{array}$ \\
\hline$X_{2}$ & Mức độ lo lắng khi bệnh DTHCP xảy ra (1-5) & + & Leslie et al. (2008); \\
\hline$X_{3}$ & Mức độ lo lắng nếu đàn heo của gia đình bị lây nhiễm (1-5) & + & Tiongco et al. (2012) \\
\hline$X_{4}$ & $\begin{array}{l}\text { Kinh nghiệm phòng các loại dịch bệnh heo khác }(0=\text { không, } 1 \\
=\text { có })\end{array}$ & + & \\
\hline $\boldsymbol{X}_{5}$ & Tuổi của chủ hộ (năm) & + & \\
\hline$X_{6}$ & Số năm đi học của chủ hộ (năm) & + & \\
\hline $\boldsymbol{X}_{7}$ & Số năm tham gia chăn nuôi heo (năm) & + & \\
\hline$X_{8}$ & Số heo thịt nuôi trong năm 2019 (con) & + & Tionoce et el (2012) \\
\hline$X_{9}$ & Số heo nái nuôi trong năm 2019 (con) & + & $11011 \mathrm{gco}$ et al. (2012) \\
\hline$X_{10}$ & Tồng diện tích trại heo $\left(\mathrm{m}^{2}\right)$ & + & \\
\hline$X_{11}$ & Số lao động trong trang trại heo (người) & + & \\
\hline$X_{12}$ & $\begin{array}{l}\text { Khoảng cách từ trại heo gia đình tới trang trại heo gần nhất } \\
\text { (m) }\end{array}$ & - & Tiongco et al. (2012) \\
\hline$X_{13}$ & Thu nhập hàng năm của hộ (1.000 đồng/năm) & + & \\
\hline
\end{tabular}

$Y$ là biến phụ thuốc trong mô hình, đây là số lượng các biện pháp an toàn sinh học và phòng dịch mà hộ nuôi heo đã áp dụng. Dựa trên các kiến nghị của FAO (2017) và tham khảo các ý kiến chuyên gia về lĩnh vực chăn nuôi, thú $\mathrm{y}, 15$ biện pháp phòng dịch được đề nghị áp dụng đối với bệnh DTHCP, ngoài ra trong quá trình phỏng vấn còn ghi nhận thêm các biện pháp khác đã được áp dụng.
$X_{I}$ là biến về kiến thức, được sử dụng trong mô hình để kiểm định liệu hiểu biết nhiều hơn về các triệu chứng của bệnh DTHCP có thúc đẩy số biện pháp phòng dịch mà người nuôi heo thực hiện hay không. Như vậy, đề tài kỳ vọng hộ có số điểm kiến thức càng cao sẽ thực hiện nhiều biện pháp phòng dịch hơn. Tổng cộng có 10 dấu hiện lâm sàng về bệnh DTHCP được báo cáo bởi FAO (2017), với 
mỗi câu trả lời đúng sẽ được tính 1 điểm và trả lời sai là 0 điểm. Tổng hợp số điểm chính là chỉ số kiến thức của mỗi hộ nuôi heo. Phương pháp đánh giá kiến thức nông nghiệp thông qua đo lường và tính điểm cũng từng được áp dụng trong nghiên cứu của Đinh Phi Hổ (2012).

Đối với các biến thể hiện thái độ của nông hộ đối với dịch bệnh, đề tài sử dụng thang đo Likert với giá trị 1 nghĩa là ít lo lắng và 5 nghĩa là rất lo lắng về sự lây lan dịch bệnh trong trường hợp địa phương xuất hiện bệnh DTHCP. Trong mô hình này có hai biến số thể hiện thái độ đó là $X_{2}$ - mức độ lo lắng khi bệnh DTHCP xuất hiện và $X_{3}-$ mức độ lo lắng nếu đàn heo của gia đình bị lây nhiễm bệnh. Hai biến này được dùng để kiểm định kỳ vọng rằng nông dân càng quan tâm với sự lây nhiễm và bùng phát bệnh DTHCP trong khu vực sẽ áp dụng nhiều biện pháp để bảo vệ trang trại của mình hơn.

$X_{4}$ là kinh nghiệm phòng dịch, kỳ vọng hộ đã có kinh nghiệm ứng phó với các dịch bệnh truyền nhiễm khác thì tích cực áp dụng nhiều biện pháp phòng bệnh DTHCP hơn.

$X_{5}$ là tuổi của chủ hộ, được dùng để kiểm định liệu người chăn nuôi càng lớn tuổi thì có hiểu biết và thực hiện nhiều biện pháp phòng bệnh DTHCPhơn không.

$X_{6}$ là số năm đi học của chủ hộ, được sử dụng để kiểm định liệu chủ hộ có trình độ học vấn cao có sẵn lòng thực hiện nhiều biện pháp phòng bệnh DTHCP hơn không.

$X_{7}$ là kinh nghiệm nuôi heo, với kỳ vọng hộ càng có nhiều kinh nghiệm sẽ nắm rõ về cách thức phòng bệnh và sẽ có ảnh hưởng tích cực lên số lượng biện pháp phòng dịch.

Ba biến $X_{8}$ - Số lượng heo thịt, $X_{9}$ - Số lượng heo nái, và $X_{10}$ - Tổng diện tích trại heo được dùng để phản ánh quy mô chăn nuôi heo. Nghiên cứu kỳ vọng đàn heo càng nhiều và diện tích chuồng trại càng lớn chứng tỏ hoạt động nuôi heo càng quan trọng trong sinh kế hộ, từ đó người nông dân sẽ thực hiện nhiều biện pháp bảo vệ hơn.

$X_{I I}$ là số lao động trong trại heo được dùng để phản ánh nguồn vốn nhân lực trong hoạt động sản xuất. Các hộ có số lượng lao động trong trang trại nuôi heo càng nhiều được kỳ vọng sẽ có nguồn lực nhiều hơn để phục vụ hoạt động phòng dịch.

$X_{12}$ là khoảng cách từ trại heo gia đình tới trại heo gần nhất được dùng để kiểm định liệu khoảng cách càng gần trang trại heo khác có làm cho hộ nuôi heo tích cực tự bảo vệ trang trại trước nguy cơ lây nhiễm hay không.

$X_{13}$ là thu nhập của nông hộ, được dùng để kiểm tra sự khác biệt giữa các khả năng tài chính và mức độ thực hiện phòng dịch lây nhiễm của hộ nuôi heo, với kỳ vọng hộ có thu nhập cao sẽ có nguồn lực tài chính mạnh hơn nên sẽ đầu tư nhiều hơn cho hoạt động phòng dịch bệnh.

\subsubsection{Phuoong pháp thu thập số liệu}

Các khu vực được lựa chọn để điều tra thu thập số liệu bao gồm các huyện: Thống Nhất, Trảng Bom và Cẩm Mỹ. Đây là các địa phương có số lượng heo lớn, trong đó số lượng heo tại huyện Thống Nhất chiếm $17 \%$ tổng số heo tại Đồng Nai, huyện Trảng Bom chiếm $13 \%$, và huyện Cẩm Mỹ chiếm $10 \%$. Ngoài ra, theo Sở NN \& PTNT tỉnh Đồng Nai (2020), đây là những địa phương có lượng heo bị tiêu hủy lớn trong bệnh DTHCP. Huyện Trảng Bom tiêu hủy 79.593 con, huyện Thống Nhất tiêu hủy 92.412 con, huyện Cẩm Mỹ tiêu hủy 29.315 con.

Cỡ mẫu tối thiểu cần đạt được khi tiến hành điều tra được tính theo công thức của Tabachnick et al. (2007): $n=50+\left(8^{*} m\right)$. Trong đó, $n$ là cỡ mẫu, $m$ là số biến độc lập trong mô hình. Có 13 biến độc lập được đưa vào hàm hồi quy, do đó cỡ mẫu tối thiểu $n$ = 154. Nghiên cứu thực hiện phỏng vấn 160 hộ nuôi heo bằng phương pháp chọn mẫu thuận tiện, sau quá trình điều tra có 20 phiếu bị loại do không đạt yêu cầu.

\section{KẾT QUẢ VÀ THẢO LUÂN}

\subsection{Mô tả mẫu điều tra}

Độ tuổi của người ra quyết định chăn nuôi trong các nông hộ được điều tra chủ yếu thuộc hai nhóm từ 50 đến dưới 60 tuổi (chiếm $38 \%$ ) và nhóm từ 40 đến dưới 50 tuổi (chiếm 35\%). Nhóm từ 60 tuổi trở lên chiếm $18 \%$ và nhóm dưới 40 tuổi chiếm $9 \%$. Độ tuổi của người quyết định chăn nuôi khá cao và nằm trong độ tuổi trung niên. Đây là những người có kinh nghiệm trong chăn nuôi heo và có đủ tiềm lực tài chính để nâng cao khả năng chăn nuôi, đem lại hiệu quả kinh tế cao hơn.

Trình độ học vấn của nông hộ là yếu tố quan trọng trong việc tiếp thu và xử lý thông tin về tình hình dịch cũng như mức độ nguy hiểm của dịch bệnh đối với heo. Trong mẫu điều tra, trình độ học vấn của người quyết định chăn nuôi đa số ở cấp 3 và cấp 2 chiếm tỷ lệ lần lượt là $42 \%$ và $38 \%$, trình độ cấp 1 là $16 \%$. Các hộ được đào tạo đại học chỉ chiếm tỷ lệ 4\%. Số năm đi học trung bình là 09 năm. Trong đó, người được phỏng vấn có số năm đi học nhiều nhất 
là 16 năm, và người có số năm đi học thấp nhất là 2 năm. Điều này cho thấy các đối tượng được khảo sát là những người có trình độ học vấn tương đối thấp.

Kinh nghiệm chăn nuôi heo của nông hộ từ 10 đến dưới 20 năm là chủ yếu (chiếm 50\%). Nhóm có kinh nghiệm chăn nuôi heo trên 10 năm chiếm tỷ lệ $23 \%$ và nhóm có kinh nghiệm từ 20 đến dưới 30 năm chiếm tỷ lệ $21 \%$. Nhóm có kinh nghiệm từ 30 năm trở lên chiếm $6 \%$. Hộ có kinh nghiệm chăn nuôi heo lớn nhất là 47 năm, nhỏ nhất là 2 năm và trung bình các nông hộ có khoảng 14 năm kinh nghiệm.

Đa số hộ có quy mô đàn heo từ 10 đến 200 con, chiếm tỷ lệ 51,0\% trong tổng 100 hộ được khảo sát. Quy mô đàn heo từ 201 đến 400 con và quy mô đàn từ 401 đến 600 chiếm tỷ lệ lần lượt là $20,0 \%$ và $13,0 \%$. Hộ có quy mô đàn trên 800 con chiếm tỷ lệ $11,0 \%$ và thấp nhất là hộ có từ 601 đến 800 con chiếm tỷ lệ 5,0\%. Hộ có quy mô đàn heo nhỏ nhất là 10 con và quy mô lớn nhất 4.000 con.

Bảng 2. Kết quả thống kê mẫu điều tra hộ nuôi heo

\begin{tabular}{lrr}
\hline Chỉ tiêu & Trung bình & Độ lệch chuẩn \\
\hline Tuổi của chủ hộ (năm) & 52 & 9 \\
Số năm đi học của chủ hộ (năm) & 9 & 3 \\
Số năm tham gia chăn nuôi heo (năm) & 14 & 7 \\
Số heo thị́t nuôi trong năm 2019 (con) & 235 & 421 \\
Số heo nái nuôi trong năm 2019 (con) & 20 & 29 \\
Tổng diện tích trại heo (m²) & 578.16 & 1233.07 \\
Số lao động trong trang trại heo (người) & 2 & 1 \\
Khoảng cách từ trại heo gia đình tới trang trại heo gần nhất $(\mathrm{m})$ & 478 & 988 \\
Thu nhập hàng năm của hộ (1.000 đồng/năm) & 280.5 & 665.98 \\
\hline
\end{tabular}

\subsection{Kiến thức phòng bệnh DTHCPcủa nông hộ tại Đồng Nai}

Kết quả khảo sát (Bảng 3) cho thấy tỷ lệ hộ có heo bị nhiễm bệnh DTHCP năm 2019 chiếm tới $70 \%$ trong mẫu khảo sát. Số hộ có lượng heo nhiễm bệnh từ 1 đến 100 con chiếm tỷ lệ $39 \%$ và số hộ có heo bệnh từ 101 đến 200 con chiếm tỷ lệ $15 \%$. Kế tiếp, số hộ có từ 201 đến 300 con và 301 đến 400 con heo bệnh chiếm tỷ lệ lần lượt là $2 \%$ và $5 \%$. Hộ có trên 400 con bị bệnh chiếm tỷ lệ $9 \%$ và hộ có số heo chết cao nhất là 2.250 con. Các hộ bị nhiễm bệnh có tỷ lệ cao nằm ở quy mô chăn nuôi vừa và nhỏ và thiệt hại mà họ phải gánh chịu chiếm tỷ trọng rất lớn trong tổng nguồn thu nhập hàng năm. Vì vậy, trong quá trình khảo sát, các hộ chăn nuôi sau khi có đàn heo bị nhiễm bệnh DTHCP thì có tỷ lệ rất cao không thể tái đàn sau dịch vì thiếu vốn.

\section{Bảng 3. Tỷ lệ nhiễm bệnh tả heo Châu Phi}

\begin{tabular}{lrr}
\hline $\begin{array}{l}\text { Số heo nhiễm } \\
\text { bệnh (con) }\end{array}$ & Tần số (hộ) & Tỷ lệ (\%) \\
\hline 0 & 42 & 30,0 \\
$1-100$ & 54 & 39,0 \\
$101-200$ & 21 & 15,0 \\
$201-300$ & 4 & 2,0 \\
$301-400$ & 7 & 5,0 \\
$>400$ & 13 & 9,0 \\
\hline Tổng & 140 & 100,0 \\
\hline
\end{tabular}

Đối với kiến thức về bệnh DTHCP, kết quả khảo sát cho thấy đánh giá của các hộ dân cho là đúng về dấu hiệu heo sốt cao $42^{\circ} \mathrm{C}$ chiếm tỷ lệ $95 \%$ và $5 \%$ còn lại hộ dân cho rằng đây không phải là triệu chứng của bệnh DTHCP. Đối với dấu hiệu heo chán ăn, đa phần người dân đều có câu trả lời đúng, chiếm tỷ lệ $95 \%$.

Có đến $82 \%$ các hộ dân đều cho rằng heo xuất huyết và da tím tái, đặc biệt là tai và bụng là triệu chứng heo đã bị nhiễm bệnh DTHCP và $18 \%$ còn lại có câu trả lời là không đồng ý. Khi khảo sát các hộ dân về dấu hiệu heo đỏ da vùng ngực, bụng, đáy chậu, đuôi và chân có phải là triệu chứng của dịch thì câu trả lời cho là đúng chiếm tỷ lệ $93 \%$ và $7 \%$ còn lại cho rằng đây không phải là triệu chứng của bệnh DTHCP.

Kế tiếp, heo ho và tăng nhiệt thì các hộ đều cho là triệu chứng của bệnh DTHCP chiếm tỷ lệ $69 \%$ và $31 \%$ còn lại thì cho là sai khi nói đến bệnh DTHCP. Dấu hiệu nôn và tiêu chảy (đôi khi có máu), theo đánh giá của hộ thì $70 \%$ câu trả lời cho rằng đây là triệu chứng của heo đã nhiễm bệnh, còn $30 \%$ còn lại không đồng ý.

Heo chảy nước mắt và mũi là triệu chứng của bệnh DTHCP, các hộ có câu trả lời đúng chiếm tỷ lệ $73 \%$ và câu trả lời sai chiếm tỷ lệ $27 \%$. Về việc heo xảy sai, các hộ khảo sát có câu trả lời đây là triệu chứng của bệnh $\mathrm{DTHCP}$ chiếm tỷ lệ là $65 \%$ còn 
$35 \%$ hộ còn lại cho rằng đây là triệu chứng của dịch heo tai xanh.

Đuôi heo dính đầy phân máu là triệu chứng của bệnh DTHCP được 53\% hộ nhận định đúng, còn 47\% còn lại nhận định sai

Cuối cùng, các hộ nhận định đúng triệu chứng heo tử vong chiếm tỷ lệ $93 \%$ và $7 \%$ nhận định sai.
Kết quả khảo sát về kiến thức đối với DTHCP cho thấy rằng người dân chỉ nắm được các triệu chứng cơ bản chứ không nắm vững toàn bộ các triệu chứng của dịch bệnh. Đa phần các hộ chỉ có khả năng nhận diện được các triệu chứng nếu đã xuất hiện trên đàn heo của hộ và không biết rõ những triệu chứng còn lại của DTHCP.

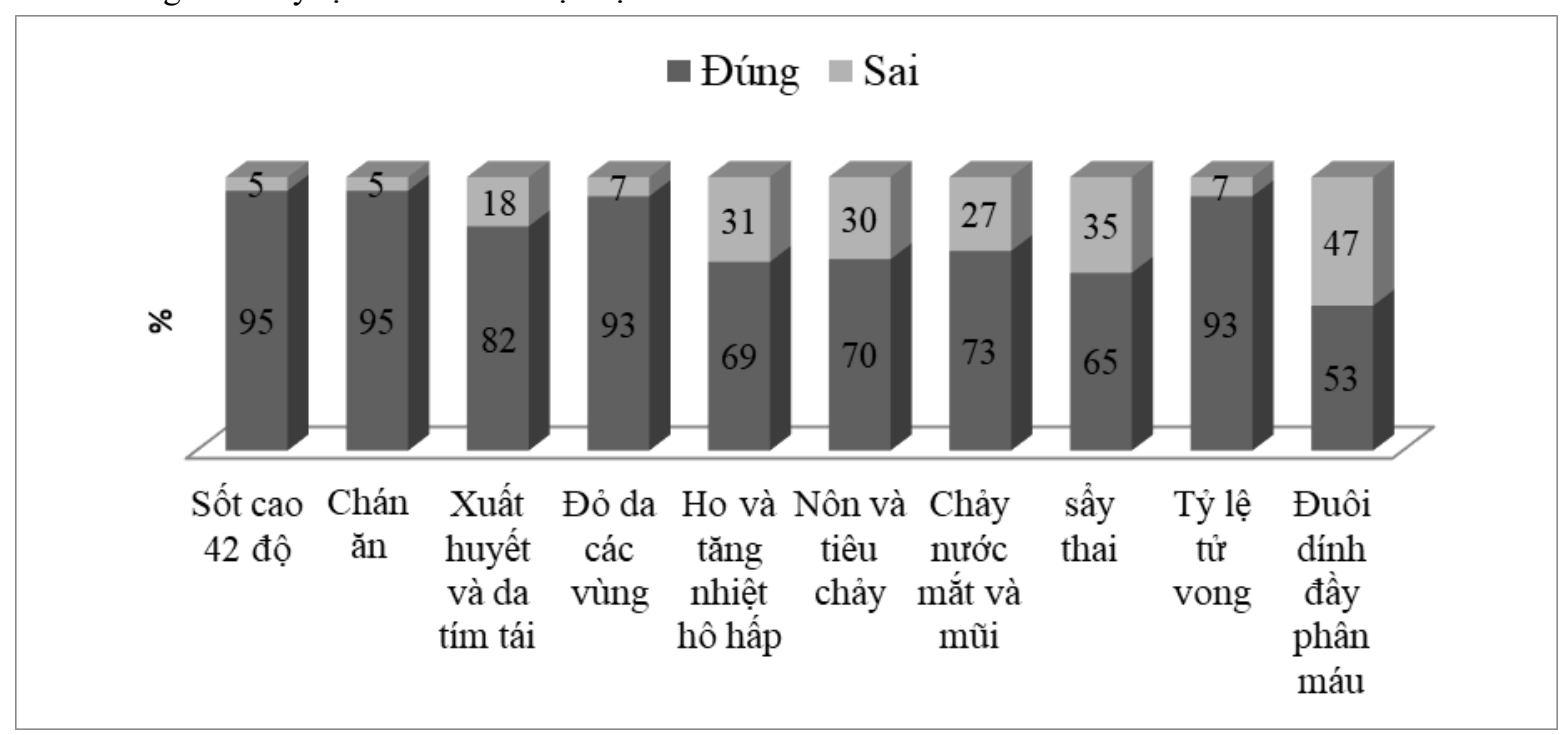

Hình 2. Kết quả nhận diện các triệu chứng của dịch tả heo Châu Phi

\subsection{Hành động phòng bệnh DTHCP của nông hộ tại Đồng Nai}

Đa phần các hộ chăn nuôi đều áp dụng từ 9 đến 12 biện pháp an toàn sinh học phòng dịch bệnh cho trang trại heo, chiếm tỷ lệ $65,0 \%$ trong tổng số hộ được khảo sát. Các hộ áp dụng từ 5 đến 8 biện pháp và từ 13 biện pháp phòng dịch bệnh trở lên chiếm tỷ lệ lần lượt là $21,0 \%$ và $13,0 \%$. Hộ áp dụng từ 1 đến 4 biện pháp phòng dịch bệnh DTHCP chiếm tỷ lệ rất nhỏ $1,0 \%$ trong tổng số hộ dân được khảo sát. Số lượng biện pháp ít nhất mà một hộ áp dụng là 3 biện pháp và nhiều nhất là 14 biện pháp trong tổng số các biện pháp được đưa ra trong bảng câu hỏi.
Các biện pháp được được thực hiện nhiều nhất lần lượt là xử lý khử trùng xung quanh trại, hạn chế người ra vào trại heo, chích vaccine, chỉ cho phương tiện ra vào trại sau khi được khử trùng, ngăn cách khu vực trong và ngoài trại,... Các biện pháp này được hơn $70 \%$ số hộ điều tra thực hiện. Ngoài ra, đáng chú ý là chỉ có $21,4 \%$ hộ thường xuyên mời cán bộ thú $\mathrm{y}$ tới kiểm tra. Hoạt động mời cán bộ thú $\mathrm{y}$ tới kiểm tra lại có tỷ lệ thực hiện rất thấp do người dân phản ánh rằng họ có thể tự mua thuốc để tiêm ngừa cho đàn heo và do bệnh dịch này chưa có bệnh pháp chữa trị nên nông dân cho rằng hiệu quả của việc mời cán bộ thú $\mathrm{y}$ tới trại heo để kiểm tra là không có. 


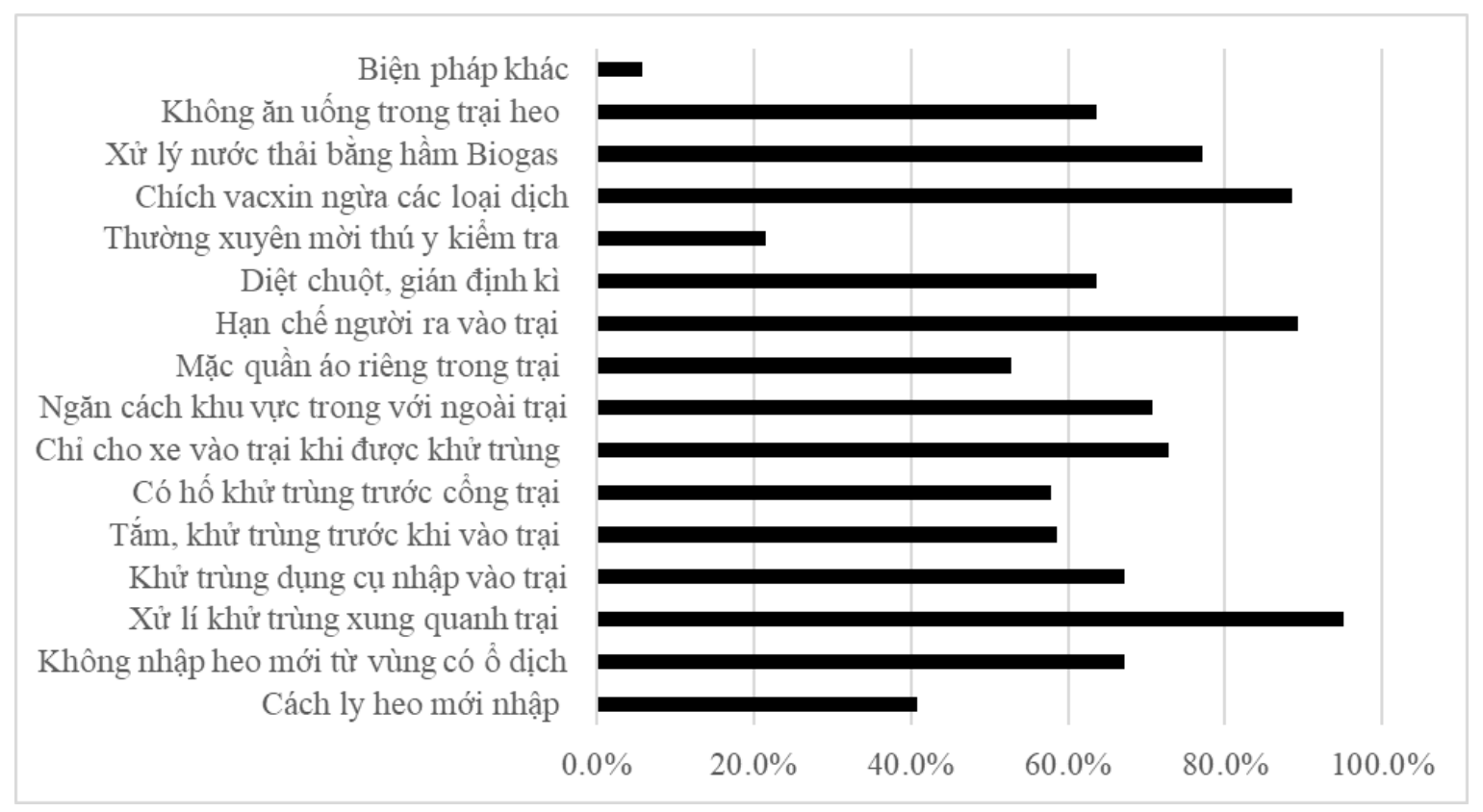

Hình 4. Tỷ lệ thực hiện của mỗi loại biện pháp phòng dịch

\subsection{Các yếu tố ảnh hưởng tới biện pháp} phòng dịch

Kết quả ước lượng độ phù hợp của mô hình cho thấy kiểm định Ominibus test có $\mathrm{p}$-value $=0,000$ chứng tỏ mô hình có ý nghĩa về mặt thống kê tại mức ý nghĩa $1 \%$. Các kết quả ước lượng của mô hình cho thấy biến Kiến thức có ý nghĩa tại mức ý nghĩa $1 \%$, các biến Mức độ lo lắng bị lây nhiễm, Kinh nghiệm phòng dịch và Khoảng cách tới trại heo khác có mức ý nghĩa tại 5\%.

Bảng 4. Kết quả ước lượng mô hình

\begin{tabular}{|c|c|c|c|c|c|c|}
\hline \multirow{2}{*}{ Biến } & \multirow{2}{*}{ Beta } & \multirow{2}{*}{$\begin{array}{l}\text { Sai số } \\
\text { chuẩn }\end{array}$} & \multicolumn{2}{|c|}{ Khoảng tin cậy 95\% } & \multirow{2}{*}{ Sig. } & \multirow{2}{*}{$\operatorname{Exp}(B)$} \\
\hline & & & Giới hạn dưới & Giới hạn trên & & \\
\hline (Intercept) & $-0,426$ & 0,5189 & $-1,443$ & 0,591 & 0,412 & 0,653 \\
\hline$X_{l}-$ Kiến thức & 0,069 & 0,0161 & 0,037 & 0,101 & 0,000 & 1,072 \\
\hline$X_{2}-$ Lo lắng dịch & 0,109 & 0,0791 & $-0,046$ & 0,264 & 0,168 & 1,115 \\
\hline$X_{3}-$ Lo lắng bị lây nhiễm & 0,339 & 0,1008 & 0,142 & 0,537 & 0,001 & 1,404 \\
\hline$X_{4}-$ Kinh nghiệm phòng dịch & 0,132 & 0,0631 & 0,009 & 0,256 & 0,036 & 1,142 \\
\hline$X_{5}-$ Tuối & $-0,005$ & 0,0037 & $-0,012$ & 0,002 & 0,196 & 0,995 \\
\hline$X_{6}-$ Học vấn & $-0,006$ & 0,0102 & $-0,026$ & 0,014 & 0,574 & 0,994 \\
\hline$X_{7}-$ Kinh nghiệm nuôi heo & 0,002 & 0,0041 & $-0,006$ & 0,010 & 0,674 & 1,002 \\
\hline$X_{8}$ - Số heo thịt & 0,000 & 0,0002 & 0,000 & 0,000 & 0,309 & 1,000 \\
\hline$X_{9}-$ Số heo nái & 0,002 & 0,0011 & $-0,001$ & 0,004 & 0,174 & 1,002 \\
\hline$X_{10}$ - Diện tích trại heo & 0,00005 & 0,00005 & $-0,00005$ & 0,00000 & 0,334 & 1,000 \\
\hline$X_{11}$ - Số lao động & $-0,02800$ & 0,03290 & $-0,09200$ & 0,03600 & 0,394 & 0,972 \\
\hline$X_{12}-$ Khoảng cách & 0,00006 & 0,00003 & 0,00000 & 0,00000 & 0,049 & 1,000 \\
\hline$X_{13}$ - Thu nhập & $-0,00004$ & 0,00005 & 0,00000 & 0,00005 & 0,357 & 1,000 \\
\hline
\end{tabular}

Biến kiến thức có ý nghĩa thống kê chứng tỏ hộ có kiến thức càng tốt về dịch bệnh có xu hướng thực hiện nhiều biện pháp phòng dịch hơn. Giá trị của hệ số hồi quy cho thấy số lượng biện pháp phòng dịch mà nông hộ thực hiện sẽ cao hơn 1,072 lần hay $7,2 \%$ khi kiến thức về bệnh DTHCP của nông hộ cao thêm một bậc.
Mức độ lo lắng nếu đàn heo của gia đình bị nhiễm dịch cho thấy nếu nông hộ càng lo ngại đàn heo cùa mình có khả năng bị nhiễm bệnh thì họ sẽ thực hiện nhiều biện pháp phòng ngừa hơn. Cụ thể, cứ với mỗi mức độ lo lắng tăng lên thì số lượng biện pháp phòng dịch được thực hiện sẽ cao hơn 1,404 hay $40,4 \%$. Điều này có thể chỉ ra rằng khi một hộ 
nhận thức về rủi ro cao hơn của sự lây lan dịch bệnh, họ cũng có thể hình thành nhận thức rằng các hành động an toàn sinh học là hiệu quả trong việc giảm thiểu rủi ro, dẫn đến hành vi thực hiện các biện pháp phòng ngừa trong thực tế cao hơn. Các kết quả về kiến thức và thái độ trong nghiên cứu này là tương đồng với nghiên cứu trước đây của Pham-Duc et al. (2019).

Biến Kinh nghiệm phòng dịch có tác động dương với số lượng biện pháp thực hiện và có ý nghĩa thống kê tại mức ý nghĩa $95 \%$. Như vậy, các hộ đã từng có kinh nghiệm đề phòng các dịch bệnh truyền nhiễm trong chăn nuôi heo trong quá khứ như dịch lở mồm long móng, dịch tai xanh thì sẽ có số lượng biện pháp phòng dịch cao hơn 1,142 lần hay $14,2 \%$ so với các hộ chưa từng có kinh nghiệm phòng dịch.

Biến khoảng cách tới trại heo khác gần nhất có ý nghĩa thống kê nhưng có hệ số hồi quy khá nhỏ, thể hiện khoảng cách tới các trại heo lân cận tuy có tác động dương lên số lượng biện pháp phòng dịch nhưng mức độ ảnh hưởng khá thấp.

\section{KẾT LUẦN VÀ ĐỀ XUẤT}

\subsection{Kết luận}

Kết quả nghiên cứu cho thấy tỷ lệ hộ chăn nuôi heo bị nhiễm bệnh DTHCP trong năm 2019 là khá cao, chiếm tới $70 \%$ trong mẫu khảo sát. Phần lớn người chăn nuôi heo đều có thể nhận diện được bệnh DTHCP với các triệu chứng như sốt cao, chán ăn, đỏ da, xuất huyết. Bên cạnh đó, vẫn có một số triệu chứng sinh học có tỷ lệ nhận diện sai nhiều như sẩy thai, ho và tăng nhiệt hô hấp, phân có máu. Qua đó thể hiện rằng người chăn nuôi heo chưa hoàn toàn nắm rõ đặc điểm của dịch bệnh này, từ đó có thể dẫn đến các rủi ro về nhận diện thiếu sót, tạo ra nguy cơ truyền nhiễm mới.

Bên cạnh đó, đa phần các hộ chăn nuôi đều áp dụng từ 9 đến 12 biện pháp an toàn sinh học phòng dịch bệnh cho trang trại heo. Các biện pháp được thực hiện nhiều nhất đó là xử lý khử trùng xung quanh trại, hạn chế người ra vào trại heo, tiêm vaccine, chỉ cho phương tiện ra vào trại sau khi được khử trùng, ngăn cách khu vực trong và ngoài trại,... Các biện pháp này được hơn $70 \%$ số hộ điều tra thực hiện.

Mặt khác, kết quả ước lượng của mô hình cho thấy các biến có ý nghĩa thống kê và tác động tích cực lên số lượng biện pháp phòng dịch của nông hộ là kiến thức, mức độ lo lắng lây nhiễm, và kinh nghiệm phòng dịch. Nếu nông hộ có kiến thức tốt hơn đối với dịch bệnh, có kinh nghiệm phòng các dịch truyền nhiễm trước đây, hay có mức độ lo lắng về rủi ro đàn heo của gia đình bị lây nhiễm thì họ sẽ tích cực thực hiện nhiều biện pháp phòng ngừa hơn.

\section{2. Đề xuất}

Các kết quả của nghiên cứu này cho thấy kiến thức của người nuôi heo đóng vai trò tích cực trong công tác phòng dịch, vì vậy cần tăng cường đẩy mạnh công tác tuyên truyền giáo dục, khuyến nông trên các phương tiện thông tin đại chúng; đảm bảo thông tin chính xác, kịp thời để người dân hiểu rõ, nắm vững kiến thức liên quan tới đặc điểm của bệnh $\mathrm{DTHCP}$ và các biện pháp phòng ngừa hiệu quả.

Yếu tố mức độ lo lắng về lây nhiễm dịch tả heo cũng góp phần nâng cao biện pháp phòng dịch, chứng tỏ rằng nếu nông hộ càng nhận thức rõ mức độ nguy hiểm và thiệt hại mà DTHCP gây ra thì họ sẽ chủ động trong công tác phòng dịch hơn. Vì vậy, cùng với hoạt động phổ biến các kiến thức phòng dịch thì cũng cần cung cấp cho người nuôi heo các thông tin về tỷ lệ heo tử vong nếu mắc bệnh và các thiệt hại về kinh tế, tài chính mà người nông dân có thể phải gánh chịu nếu bị lây nhiễm.

Những nông hộ đã có kinh nghiệm lâu năm trong việc phòng chống các bệnh truyền nhiễm trong chăn nuôi heo cần phải là những người đi tiên phong trong công tác phòng dịch DTHCP và hỗ trợ những người nuôi heo khác về kiến thức và các biện pháp phòng ngừa hiệu quả. Các cơ quan, chính quyền địa phương cần tận dụng các nguồn lực địa phương này để những người nông dân có thể chia sẻ hiểu biết cho nhau thông qua việc tổ chức các buổi tập huấn, tọa đàm liên quan tới phòng dịch DTHCP tại các xã, ấp.

Ngoài các kiến nghị trên, sự hỗ trợ kinh phí từ các cơ quan chính quyền là hết sức cần thiết trong công tác phòng, chống dịch. Cần tiếp tục duy trì cơ chế hỗ trợ người chăn nuôi, hộ nông dân, chủ trang trại, tổ hợp tác, hợp tác xã sản xuất trong lĩnh vực chăn nuôi có heo buộc phải tiêu hủy do bệnh DTHCP với mức hợp lý trên cơ sở giá của heo giống, chi phí chăn nuôi heo và phù hợp cho từng loại heo.

Để tránh tình trạng bán chạy bán tháo heo đã nhiễm bệnh, cần theo dõi, khuyến khích các cơ sở, doanh nghiệp tại các địa phương triển khai thực hiện việc thu mua heo sạch, không nhiễm bệnh nhằm giảm thiểu lây lan dịch bệnh, giảm thiểu thiệt hại cho người chăn nuôi để giữ ốn định giá heo và có nguồn thực phẩm an toàn cung cấp cho nhu cầu thị trường. Bên cạnh đó, cần phải tăng cường kiểm tra, 
kiểm soát thị trường nhằm ngăn chặn việc buôn bán, vận chuyển heo, sản phẩm heo không rõ nguồn gốc, không bảo đảm các yêu cầu vệ sinh thú y và an toàn thực phẩm.

\section{LỜI CẢM ƠN}

Nhóm tác giả xin chân thành cảm ơn Trường Đại học Nông Lâm Thành phố Hồ Chí Minh đã tài trợ kinh phí và tạo điều kiện để thực hiện nghiên cứu này.

\section{TÀI LIỆU THAM KHẢO}

Beltran-Alcrudo, D., Arias, M., Gallardo, C., Kramer, S., \& Penrith, M. (2017). African swine fever: detection and diagnosis - A manual for veterinarians (Vol. 19). Rome: Food and Agriculture Organization of the United Nations (FAO).

Chenais, E., Boqvist, S., Sternberg-Lewerin, S., Emanuelson, U., Ouma, E., Dione, M., Aliro, T., Crafoord, F., Masembe, C., \& Ståhl, K. (2017). Knowledge, Attitudes and Practices Related to African Swine Fever Within Smallholder Pig Production in Northern Uganda. Transboundary and Emerging Diseases, 64(1), 101-115. doi:https://doi.org/10.1111/tbed.12347

Costard, S., Mur, L., Lubroth, J., Sanchez-Vizcaino, J. M., \& Pfeiffer, D. U. (2013). Epidemiology of African swine fever virus. Virus Research, 173(1), 191-197.

Di Giuseppe, G., Abbate, R., Albano, L., Marinelli, P., \& Angelillo, I. F. (2008). A survey of knowledge, attitudes and practices towards avian influenza in an adult population of Italy. $B M C$ Infectious Diseases, 8(1), 36. doi:https://doi.org/10.1186/1471-2334-8-36

Đinh Phi Hổ. (2012). Phuoong pháp nghiên cúu định luợng và nhũng nghiên cưu thực tiễn trong kinh tế phát triển - nông nghiẹp. Tp. Hồ Chí Minh: NXB Phương Đông.

FAO. (2019). African Swine Fever: A viral disease with $100 \%$ fatality rate. http://www.fao.org/myanmar/news/detailevents/en/c/1177347/

Fielding, R., Lam, W. W. T., Ho, E. Y. Y., Lam, T. H., Hedley, A. J., \& Leung, G. M. (2005). Avian influenza risk perception, Hong Kong. Emerging infectious diseases, 11(5), 677-682. doi:10.3201/eid1105.041225

Gardner, W., Mulvey, E. P., \& Shaw, E. C. (1995). Regression analyses of counts and rates: Poisson, overdispersed Poisson, and negative binomial models. Psychological bulletin, 118(3), 392-404. doi:https://doi.org/10.1037/0033-2909.118.3.392

Huang, C. L. (1993). Simultaneous-Equation Model for Estimating Consumer Risk Perceptions,
Attitudes, and Willingness-to-Pay for ResidueFree Produce. Journal of Consumer Affairs, 27(2), 377-396.

doi:https://doi.org/10.1111/j.17456606.1993.tb00754.x

Jolly, C. M., Bayard, B., Awuah, R. T., Fialor, S. C., \& Williams, J. T. (2009). Examining the structure of awareness and perceptions of groundnut aflatoxin among Ghanaian health and agricultural professionals and its influence on their actions. The Journal of Socio-Economics, 38(2), 280-287.

doi:https://doi.org/10.1016/j.socec.2008.05.013

Lê Thị Mai Hương. (2017). Phát Triển Mô Hình Trang Trại Chăn Nuôi Heo Theo Huoóng Hội Nhập Quốc Tế Ở Đồng Nai. (Luận văn Tiến sĩ), Trường Đại Học Kinh Tế - Luật, Hồ Chí Minh.

Le, V. P., Jeong, D. G., Yoon, S.-W., Kwon, H.-M., Trinh, T. B. N., Nguyen, T. L., Bui, T. T. N., Oh, J., Kim, J. B., Cheong, K. M., Van Tuyen, N., Bae, E., Vu, T. T. H., Yeom, M., Na, W., \& Song, D. (2019). Outbreak of African Swine Fever, Vietnam, 2019. Emerging infectious diseases, 25(7), 1433-1435.

doi:https://doi.org/10.3201/eid2507.190303

Leslie, T., Billaud, J., Mofleh, J., Mustafa, L., \& Yingst, S. (2008). Knowledge, attitudes, and practices regarding avian influenza (H5N1), Afghanistan. Emerging infectious diseases, 14(9), 1459-1461. doi:10.3201/eid1409.071382

Nguyễn Trí. (2020). Đồng Nai công bố hết dịch tả heo châu Phi. https://tuoitre.vn/dong-nai-congbo-het-dich-ta-heo-chau-phi2020032511180294.htm

Penrith, M.-L. (2009). African swine fever. Onderstepoort Journal of Veterinary Research, 76(1), 91-95.

Pham-Duc, P., Cook, M. A., Cong-Hong, H., Nguyen-Thuy, H., Padungtod, P., Nguyen-Thi, H., \& Dang-Xuan, S. (2019). Knowledge, attitudes and practices of livestock and aquaculture producers regarding antimicrobial use and resistance in Vietnam. Plos One, 14(9). doi:https://doi.org/10.1371/journal.pone.0223115

Sở NN \& PTNT tỉnh Đồng Nai. (2020). Báo cáo tình hình thực hiện nhiệm vụ năm 2019, giải pháp năm 2020 ngành Nông nghiệp và Phát triển nông thôn.

Suphunnakul, P., \& Maton, T. (2009). Community participation as a key element in prevention and control of avian influenza in Song Phi Nong District, Suphan Buri Province. J Public Health (Oxf), 39(1), 61-73.

Swai, E. S., \& Lyimo, C. J. (2014). Impact of African swine fever epidemics in smallholder pig production units in Rombo district of Kilimanjaro, Tanzania. Livestock Research for Rural Development, 26(2), Article-32. 
Tabachnick, B. G., Fidell, L. S., \& Ullman, J. B. (2007). Using multivariate statistics (Vol. 5): Pearson Boston, MA.

Tiongco, M., Narrod, C., Scott, R., Kobayashi, M., \& Omiti, J. (2012). Understanding Knowledge, Attitude, Perceptions, and Practices for HPAI Risks and Management Options Among Kenyan Poultry Producers. In D. Zilberman, J. Otte, D. Roland-Holst, \& D. Pfeiffer (Eds.), Health and Animal Agriculture in Developing Countries (pp. 281-304). New York, NY: Springer New York.

Tổng cục thống kê. (2020). Số lượng lợn tại thời điểm 1/10 hàng năm phân theo địa phưong.

Vergne, T., Chen-Fu, C., Li, S., Cappelle, J., Edwards, J., Martin, V., Pfeiffer, D. U., Fusheng, G., \& Roger, F. L. (2017a). Pig empire under infectious threat: risk of African swine fever introduction into the People's Republic of China. Veterinary Record, 181(5), 117. doi:https://doi.org/10.1136/vr.103950

Vergne, T., Gogin, A., \& Pfeiffer, D. U. (2017b). Statistical Exploration of Local Transmission Routes for African Swine Fever in Pigs in the Russian Federation, 2007-2014. Transboundary and Emerging Diseases, 64(2), 504-512. doi:https://doi.org/10.1111/tbed.12391

Vinuela, E. (1985). African swine fever virus. In Iridoviridae (pp. 151-170): Springer.

WHO. (2008). Advocacy, communication and social mobilization for TB control: a guide to developing knowledge, attitude and practice surveys (9241596171). Retrieved from https://apps.who.int/iris/handle/10665/43790 